\section{IUMRS Seeks Nominations for Sōmiya Award}

\section{www.iumrs.org}

The International Union of Materials Research Societies (IUMRS) is seeking nominations for the annual Somiya Award, which recognizes research on materials conducted by a research team whose members are drawn from at least two continents. The award recipients, selected by the IUMRS Commission on Awards, will be honored during an award ceremony commemorating the occasion and will receive free registration to the annual IUMRS International Conference to be held in Singapore in July, where they will present their work.

The criteria used by the IUMRS Commission on Awards for selection include the following:

- The team to be honored must have collaborated across at least two continents (e.g., North America, Europe, Asia, Australia) some time during the last decade. nized by the international materials community. ety is also a major factor. northwestern.edu.
- The collaborative work must be of the highest quality and well recog-

- The impact on technology or soci-

Any member of an adhering IUMRS Society is invited to nominate the achievements of any such team for the award. Nominators should note that the cooperative element is a major factor in the selection of the recipients, in addition to the novelty and importance of the research.

The deadline for nominations for the 2005 Sōmiya Award is May 15. Nomination forms can be accessed from the IUMRS Web site at www.iumrs.org. For more information, e-mail a-muller@

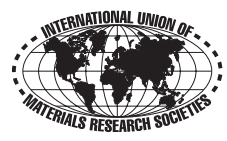

\section{International Materials Research Congress to be Held in Cancun in August 2005 www.viep.buap.mx/imrc2005.htm}

Cancun, Mexico will be the host city to the combined efforts of several professional societies as they provide a multidisciplinary forum on new directions in materials research and technology on August 21-25, 2005.

The Academia Mexicana de Ciencia de Materiales, the International Union of Materials Research Societies, and the National Association of Corrosion Engineers NACE International Section Mexico announce the XIV International Materials Research Congress, the 10th anniversary of the Materials World Network, and the IV National Association of Corrosion Engineers NACE International Section Mexico. Pedro Hugo Hernández Tejeda (Benemerita Universidad Autonoma de Puebla) is the general chair and president of MRS-Mexico.

These meetings have been organized annually and provide an interactive forum for discussing the advances in synthesis, characterization, properties, processing, applications, basic research trends, corrosion prevention, and other issues related to the materials sciences area. The Materials World Network $(\mathrm{MWN})$ is a global meeting place for those interested in materials science, education, and technology. During the celebration, the conference will provide a venue in which attendees can meet with global funding managers and learn about ongoing international research collaborations.

The 21 symposium topics include Nanostructured Materials and Nanotechnology; Theory and Computer Simulation of Complex Materials; New Trends in Polymer Chemistry and Characterization; Alloys, Composites, and Interphases; Archaeology and Arts Issues in Materials Science; Ecomaterials; and Inter-American Collaboration in Materials.

Plenary speakers include Alvin D. Compaan (the University of Toledo), on the topic of "Photovoltaics: Clean Power for the 21st Century," and Thom Mason from the Spallation Neutron Source in the United States.

The abstract deadline is May 15, 2005.

For further information, write to 29 Oriente \#601-1, Col. Ladrillera de Benítez, C.P. 72540, Puebla, Mexico; phone or fax 52-222-2-11-43-93 or 52-222-2-11-94; e-mail imrc@mail.buap.mx; or access Web site www.viep.buap.mx/imrc2005.htm/.

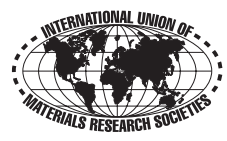

MIR

Future Meetings

2005 FALL MEETING

Nov. 28-Dec. 2

Exhibit: Nov. 29-Dec. 1

Boston, MA

Meeting Chairs:

Yang-Tse Cheng

General Motors R\&D Ctr.

yang.t.cheng@gm.com

David S. Ginley

National Renewable

Energy Laboratory

david_ginley@nrel.gov

Kathryn E. Uhrich

Rutgers University

uhrich@rutchem.rutgers.edu

Ralf B. Wehrspohn

Paderborn University

wehrspohn@physik.uni-paderborn.de

\section{SPRING MEETING}

April 17-21

Exhibit: April 18-20

San Francisco, CA

Meeting Chairs:

J. Charles Barbour

Sandia National Laboratories

jcbarbo@sandia.gov

Paul S. Drzaic

Alien Technology Corporation

pdrzaic@alientechnology.com

Gregg S. Higashi

Applied Materials

gregg_s_higashi@amat.com

\section{Viola Vogel}

Swiss Federal Institute

of Technology, ETH

viola.vogel@mat.eth.eh 